\title{
Cloning and characterization of a chicken protein tyrosine phosphatase, CPTP1
}

\author{
Choong Won Kim ${ }^{1}$, Eun Joo Jung ${ }^{1}$, and \\ Yoon-Se Kang ${ }^{1,2}$ \\ 1 Department of Biochemistry and Gyeongsang Institute of Cancer \\ Research, Gyeongsang National University College of Medicine, \\ Chinju 660-280, Korea \\ 2 Corresponding author
}

Accepted 12 December 1996

Abbreviations used: PTK, protein tyrosine kinase; CPTP, chicken protein tyrosine phosphatase; HPTP1B, human placenta protein tyrosine phosphatase 1B; RPTP, rat brain PTP; GST, glutathione S- transferase; pNPP, p-nitrophenyl phosphate

\begin{abstract}
Protein tyrosine phosphorylation and dephosphorylation are an important regulatory reactions in cell physiology. We have cloned a cDNA that encode a cytosolic protein tyrosine phosphatase (CPTP1) from chicken intestine cDNA library. Amino acid sequence identity between the CPTP1 and low molecular weight form of human placenta enzyme (HPTP1B) was 92\%. CPTP1 lacked 13 amino acids in $\mathrm{N}$-terminal region, while it had an additional 48 amino acids in the $\mathrm{C}$-terminal region in comparison with the truncated form of HPTP1B of 321 amino acids. This C-terminal sequence was different from those of all known PTPs. The CPTP1 does not have a membrane targeting or nuclear localization sequences at its $\mathrm{C}$-terminus like other PTPs such as HPTP1B and murine homolog of the human T-cell protein tyrosine phosphatase (MPTP) do. The cloned cDNA has been expressed in $E$. coli and purified by affinity chromatography. Dephosphorylation kinetics of this enzyme closely resembled those of the known PTPs. The dephosphorylation reaction required a reducing agent such as glutathione and dithiothreitol and was inhibited by sodium vanadate and formaldehyde. Deletion of $\mathbf{7 2}$ amino acids from $\mathbf{C}$-terminal side of CPTP1 gene resulted in higher expression in $E$. coli and more potent phosphatase activity than wild type CPTP1 gene product. This result suggests that the C-terminal region of the CPTP1 protein negatively regulates phosphatase activity. These results also imply that CPTP1 might be a nontransmembrane-type enzyme with a structure
\end{abstract}

and localization specificity distinct from other known cytosolic PTP1B type homolog.

Keywords: chicken, protein tyrosine phosphatase

\section{Introduction}

Phosphorylation of proteins on tyrosyl residues is a mechanism by which multiple cellular events are regulated (Cantley et al., 1991). At steady state, the phosphorylation of a tyrosyl residue depends on the relative activities of protein tyrosine kinases (PTKs) and protein tyrosine phosphatases (PTPs). Most works on phosphorylation of a tyrosyl residue until 1988 had been focused on PTKs but with the determination of partial amino acid sequence of a PTP, which led to the cloning of a whole PTP gene in human by Tonks and his coworkers (Charbonneau et al., 1988), PTP begins to attract as much attention as PTKs. However, the function and substrate specificity of the PTPs are still unclear but there are many convincing line of reports that it might underlie the dephosphorylation of specific key regulatory proteins. On the basis of their function, structure and sequence, the PTPs can be grouped into transmembrane and nontransmembrane families (Fischer et al., 1991).

The prototype of nontransmembrane PTP, HPTP1B, was originally identified as the major PTP in human placenta (Tonks et al., 1988a, b). The sequence of this protein purified from placenta is truncated at amino acid 321. Thus it lacks the hydrophobic C-terminus. Molecular cloning of human (Chernoff et al., 1990; Brown-Shimer et al., 1990) and rat brain PTP (Guan et al., 1990) identified proteins of 435 and 432 amino acids, respectively, possessing two distinct structural motifs: the phosphatase catalytic domain (approximately amino acid residues 40-276) and a highly hydrophobic stretch of amino acids near the C-terminus (amino acid residues 401-431 in human) (Charbonneau et al., 1989).

By analogy to the results that the known localization of non-transmembrane tyrosine kinase and their substrates, it seemed likely that the cytosolic PTPs would be found in plasma membrane, cytoskeleton, and/or nucleus. A PTP closely related to PTP1B from human T-cell (TPTP) has been cloned and when it is overexpressed in baby hamster kidney cell, the PTP associates exclusively with particular fraction (Cool et al., 1990). Further the association of the TPTP with the particulate has been shown to require its $98 \mathrm{C}$-terminal amino acids. Subsequently, using truncations and 
domain swap experiments Frangioni et al. (1992) showed that C-terminal 35 amino acids of PTP1B were both necessary and sufficient for targeting to the endoplasmic reticulum. These discovery of the role of C-terminal hydrophobic region affords to propose the so-called localization specificity of these enzymes and contributes to elucidate the role of this region in PTP1B isoform.

To understand the role of a PTP in chicken undergoing rapid cell proliferation and differentiation in embryos, we cloned cDNA of a PTP called CPTP1 and deduced its amino acid sequences. The CPTP1 did not have a hydrophobic $\mathrm{C}$-terminal targeting or localization sequences found in the PTP homologs of higher eukaryotes. This paper describes the expression of CPTP1 in E.coli, purification by affinity chromatography and its kinetic characterization.

\section{Materials and Methods}

\section{Materials}

Restriction enzymes, T4 DNA ligase, calf intestinal alkaline phosphatase, and Klenow DNA polymerase were purchased from Boehringer Mannheim $(\mathrm{GmbH}$, Germany) or Bethesda Research Labo-ratories (Gaithersburg, MD). All chemicals, unless otherwise specified, were purchased from Sigma Chemical Company (St. Louis, MO). Yeast extract, tryptone, and bacto-agar were purchased from Difco. $\left[\alpha^{-}{ }^{32} \mathrm{P}\right] \mathrm{dCTP}$ and $\left[\alpha-{ }^{35}\right.$ S $]$ dATP were from New England Nuclear and Amersham. All sequencing reactions were performed using Sequenase kit (United States Biochemical).

\section{Isolation of cDNA clones from chicken intestine cDNA library}

A chicken intestine cDNA library in $\lambda$ gt10 (provided by $P$. Matsudaira, Whitehead Institute for Biomedical Research, MIT), was plated at a density of 50,000 plaques/150-mm plate. Plaques were transferred to nitrocellulose filters according to the method of Grunstein and Hogness (1975). A total 500,000 recombinants were initially screened using a ${ }^{32} \mathrm{P}$. labeled EcoRV-EcoRV 291 bp fragment (probe A) encoding amino acid sequences of the highly conserved catalytic domain within HPTP1B. Hybridization was carried out by a standard methods (Sambrook et al., 1990). Nine positive clones were selected, subcloned into M13mp18/19, or pUC19 cloning vectors, and subjected to sequence analysis by the dideoxy nucleotide chain termination method (Sanger et al., 1977).

\section{Gel-directed Northern and Southern hybridization}

For Northern analysis, 17 and $34 \mu \mathrm{g}$ of total RNA or 10 $\mu \mathrm{g}$ of poly $(\mathrm{A})^{+}$RNA isolated from 4 day chicken embryos were denatured in $25 \mu \mathrm{l}$ of solution containing 1XMNE (22 mM morpholinopro-panesulfonic acid, $\mathrm{pH}$ 7.0/5 mM sodium acetate/0.1 mM EDTA), 6.15 M formaldehyde, $17.5 \%$ formamide, and $0.01 \%$ bromophenol blue. The mixture was incubated at $60^{\circ} \mathrm{C}$ for 5 min, and then quick-chilled. Samples were electrophoresed on $1 \%$ formaldehyde/agarose gel and soaked in distilled water for $2 \mathrm{~h}$. The gel was washed in 6XSSC ( $1 \times S S C=0.15 \mathrm{M}$ sodium chloride/ $0.015 \mathrm{M}$ sodium citrate, $\mathrm{pH}$ 7.0) for $10 \mathrm{~min}$, and dried at $60^{\circ} \mathrm{C}$ for $1 \mathrm{~h}$ under the vacuum. Prior to prehybridization the dried gel was soaked in $6 \times$ SSC for $5 \mathrm{~min}$. The gel was prehybridized in prehybridization solution containing $6 \mathrm{x}$ SSC/5XDenhardt's solution/0.05\% sodium pyrophosphate $/ 100 \mu \mathrm{g} / \mathrm{ml}$ herring sperm DNA $/ 0.5 \%$ SDS at $65^{\circ} \mathrm{C}$ for $2 \mathrm{~h}$, and hybridized in solution containing $6 \times \mathrm{SSC} / 1 \times$ Denhardt's solution $/ 100 \mu \mathrm{g} / \mathrm{ml}$ yeast tRNA/0.05\% sodium pyrophosphate/radiolabeled probe A $\left(2-3 \times 10^{6} \mathrm{cpm} / \mathrm{ml}\right)$ at $65^{\circ} \mathrm{C}$ overnight. The gel was washed twice in $2 \times S S C / 0.1 \%$ SDS at room temperature for $5 \mathrm{~min}$ and three times for $30 \mathrm{~min}$ at $65^{\circ} \mathrm{C}$ in the same solution. The gel was dried at $60^{\circ} \mathrm{C}$ for $30 \mathrm{~min}$ under the vacuum and visualized by autoradiography with intensifier screen at $-70^{\circ} \mathrm{C}$.

For Southern hybridization, $\lambda$ gt10-cDNAs isolated from 9 positive clones were digested with EcoRI and Notl, and the insert DNA was analyzed on $1 \%$ agarose gel in TAE buffer ( $40 \mathrm{mM}$ Tris, $12 \mathrm{mM}$ sodium acetate, 2 mM EDTA, $\mathrm{pH}$ 8.3). The gel was dried under the vacuum at $60^{\circ} \mathrm{C}$ for $1 \mathrm{~h}$. The gel was denatured in a solution containing $0.2 \mathrm{M} \mathrm{NaOH} / 0.6 \mathrm{M} \mathrm{NaCl}$ at room temperature for $30 \mathrm{~min}$ prior to prehybridization, and then neutralized in a solution containing $0.2 \mathrm{M}$ Tris $(\mathrm{pH}$ 7.4)/0.6 M NaCl at room temperature for $30 \mathrm{~min}$ twice. The other steps were done as described for the Northern analysis.

\section{Construction of GST-PTP fusion plasmids}

The CPTP1 cDNA in pUC19 was digested partially with $E c o R I$ and linked in frame to the glutathione $S$ transferase (GST) gene of the pGEX-2T vector (Smith and Johnson, 1988) to generate the GST-CPTP1 fusion protein coding for amino acids 1-356 of CPTP1. For generation of the GST-CPTP1-1 fusion protein lacking in 72 amino acids in C-terminal side of CPTP1, pUC19CPTP1 was digested with EcoRI and Bg/ll and filled using the Klenow fragment of DNA polymerase I. This CPTP1-1 cDNA fragment was ligated to the Smaldigested $p G E X-1 \mathrm{~N}$ vector. For generation of another GST-HPTP1B coding for amino acids 1-321 of HPTP1B, the truncated HPTP1B cDNA fragment was ligated to the Smal-digested pGEX-2T. The resulting plasmids contained the coding sequence for CPTP1, CPTP1-1 and HPTP1B in frame with GST gene and 
were transformed into E. coli strain BL21(DE3).

\section{Expression and purification of GST-PTP fusion proteins in E. coli}

Overnight cultures of $E$. coli transformed with parental or recombinant pGEX plasmids were diluted 1:10 in fresh LB medium containing ampicillin $(100 \mu \mathrm{g} / \mathrm{ml})$ and grown for $1 \mathrm{~h}$ at $37^{\circ} \mathrm{C}$ before adding isopropyl $\beta$-Dthiogalactopyranoside. When the cells had reached an $\mathrm{OD}_{600}$ of $0.6-1.0$, isopropyl $\beta$-D-thiogalactopyranoside (1 $\mathrm{mM}$ ) was added to the medium and the culture was incubated for $3 \mathrm{~h}$. In a typical isolation of recombinant protein, $2.5 \mathrm{~g}$ of cells were resuspended in $15 \mathrm{ml}$ of 130 $\mathrm{mM} \mathrm{NaCl} / 20 \mathrm{mM}$ sodium phosphate $(\mathrm{pH} 7.4)$ containing $1 \%(\mathrm{v} / \mathrm{v})$ Triton $\mathrm{X}-100$ and were broken by sonication (Carlino et al., 1992). The lysate was centrifuged at 10,000 r.p.m. for $7 \mathrm{~min}$, and the supernatant was mixed with $500 \mu \mathrm{l}$ of glutathione agarose that had been equilibrated with the above buffer at $4^{\circ} \mathrm{C}$. The beads were collected by centrifugation at 3,000 r.p.m. for 1 min and washed three times with 10 volumes of $50 \mathrm{mM}$ Tris $(\mathrm{pH} 7.4) / 150 \mathrm{mM} \mathrm{NaCl}$ buffer. Fusion proteins were eluted with $50 \mathrm{mM}$ Tris ( $\mathrm{pH} 8.0$ ) containing $20 \mathrm{mM}$ reduced glutathione. Absorption of fusion protein to the glutathione agarose beads and subsequent elution were done within $5 \mathrm{~min}$.

\section{Kinetic assay of CPTP1, CPTP1-1, and HPTP1B}

Reactions were carried out in a volume of $100 \mu \mathrm{l}$ containing $0.1 \mathrm{M} \mathrm{p}$-nitrophenyl phosphate (pNPP), 0.1 $M$ Tris (pH 8.0), $0.25 \mathrm{M} \mathrm{NaCl}, 5 \mathrm{mM}$ EDTA, and $10 \mathrm{mM}$ dithiothreitol or glutathione at $37^{\circ} \mathrm{C}$ for $10 \mathrm{~min}$ (Dunphy et al., 1991). At the end of the incubation, the reaction was terminated by the addition of $200 \mu \mathrm{l}$ of $0.1 \mathrm{M}$ $\mathrm{NaOH}$. Absorbance of reaction mixture at $410 \mathrm{~nm}$ was measured with the spectrophotometer. Assay buffer lacking PTP in the reaction mixture was used as a blank.

\section{Results and Discussion}

\section{Isolation of a CPTP cDNA}

To study the expression of PTPs in chicken embryo, total RNA was isolated from 4 day embryos. Poly $(A)^{+}$ RNA was also isolated from total RNA by oligo(dT)cellulose. Total RNA and poly $(A)^{+}$RNA samples were electrophoresed and hybridized with the ${ }^{32} \mathrm{P}$-labeled probe A. As shown Figure 1, a single RNA band of about $5 \mathrm{~kb}$ was detected in the chicken embryo extracts. This result suggested that a 5-kb transcript of PTP was expressed in chicken embryo.

We then screened chicken intestine cDNA library in $\lambda$ gt10 with probe A. Among 500,000 recombinants, 9 positive clones were selected finally. To determine whether the clones were related, they were digested with EcoRI and Notl, and analyzed by Southern hybridization with probe A (Figure 2) The result showed that cDNAs of all selected clones had two EcoRI fragments (960 bp, $780 \mathrm{bp}$ ) and one Notl fragment

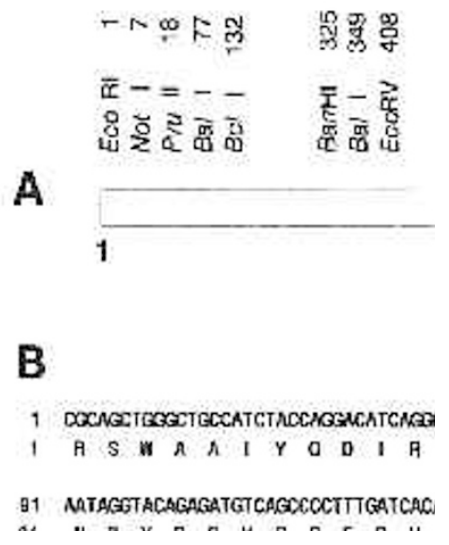

Figure 1. Expression of a CPTP mRNA in 4-day chicken embryos. Total RNA and poly $(A)^{+}$RNA were isolated from 4-day chicken embryos, and separated on $1 \%$ formaldehyde/agarose gel. Lane 1 and 2 contain $17 \mu \mathrm{g}$ and $34 \mu \mathrm{g}$ of the total RNA, respectively. By comparison, $10 \mu \mathrm{g}$ of poly $(\mathrm{A})^{+} \mathrm{RNA}$ is loaded in lane 3 . Expression of a CPTP mRNA was examined by hybridization with the ${ }^{32} \mathrm{P}$-labeled probe $\mathrm{A}$ by geldirected Northern hybridization method as described under "Materials and Methods".

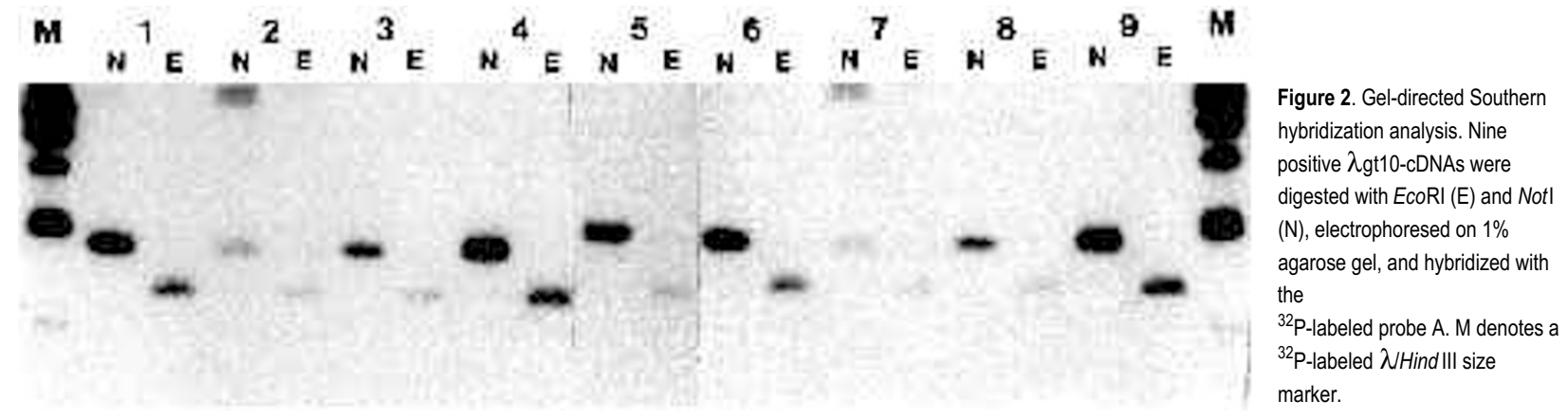


(1731 bp), suggesting they are the same cDNAs.

\section{DNA sequence analysis}

A diagrammatic representation of CPTP1 with restriction enzyme sites and deduced amino acid sequence are illustrated in Figure $3 \mathrm{~A}$ and $3 \mathrm{~B}$, respectively. The isolated CPTP1 CDNA consisted of 1,718 nucleotides with an open reading frame coding for 356 amino acid residues. The open reading frame terminates with a TAA stop codon followed by 646 bp of $3^{\prime}$ untranslated region. We did not find a polyadenylylation signal site or a $3^{\prime}$ poly $(A)^{+}$tail, suggesting that intact mRNA of CPTP1 contains more nucleotides than the isolated cDNA clone. The other PTPs without polyadenylylation signal and $3^{\prime}$ poly $(A)^{+}$ tail have been reported (Cool et al., 1989; Guan et al., 1991). We note that Northern hybridization analysis showed a clear band of $5 \mathrm{~kb}$ (Figure 1). These results indicated that about 5-kb band could be another CPTP or CPTP1 may be a truncated form in the $\mathrm{N}$-terminal region.

\section{Analysis of amino acid of CPTP1 and comparison with other nontransmembrane- type PTPs}

Deduced amino acid sequence of CPTP1 was aligned with yeast and mammalian nontransmembrane-type PTPs and the result is shown in Figure 4. Sequence identity between these enzymes was more than $95 \%$ in the conserved central region, but the sequences in the $\mathrm{N}$ - and $\mathrm{C}$-terminal regions were distinct. The CPTP1 sequence contained a single highly conserved PTP catalytic sequence (VHCSAGIGRSG) and was shorter than those of other mammalian PTPs. In the catalytic sequence, there was a nucleotide-binding fold, GXGXXG, which was also found in various dehydrogenases, G-proteins and protein kinases (Pot et al., 1991). Nucleotide-binding fold was also located within the highly conserved active site region of other PTPs. A second absolutely conserved residue, aspartic acid, was observed in WPDF sequence. It was located at 34 $\mathrm{N}$-terminal side of cysteine in catalytic motif. Located on a mobile loop in three-dimensional structure this aspartic acid can donate a proton acting as a general acid, enhancing catalytic activity of this enzyme.

CPTP1 contained another PTP motif FWXMVW and FKVRES, which are similar to FLVRES originally identified in the $\mathrm{SH} 2$ domain of the tyrosine kinase Src. The presence of $\mathrm{SH} 2$-like consensus sequence within CPTP1 suggested that CPTP1 binds to phosphotyrosine of target proteins. In the CPTP1 sequence there were five casein kinase II (CKII) phosphorylation motifs (S/TXXD/E) and one mitogen-activated protein kinase phosphorylation site (P-E-S-P), suggesting that CPTP1 activity is regulated by phosphorylation at these sites.

The deduced amino acid sequence of isolated CPTP 1 cDNA showed $92 \%$ sequence identity to the corresponding 321 residues of the HPTP1B (Figure 4). In comparison with truncated 321 amino acid HPTP1B, CPTP 1 lacked 13 amino acids in $\mathrm{N}$-terminal region, while it had an additional 48 amino acids in the Cterminal region. Amino acid sequence of this region completely differed from the $\mathrm{C}$-terminal region of full

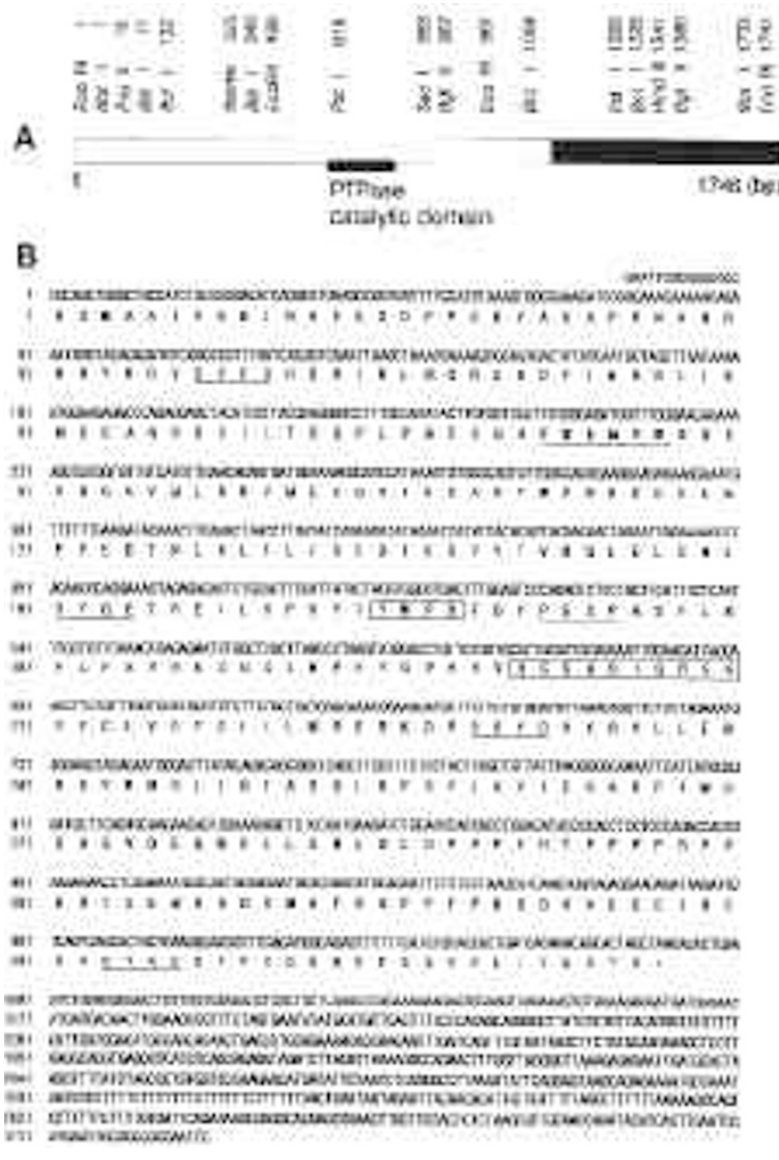

Figure 3. Restriction map, nucleotide and deduced amino acid sequences of the CPTP1 cDNA. (A) Restriction map of the CPTP1 cDNA. 3' untranslated regions are depicted by the black box, while the coding region is designated by the open box. The numbers at each restriction site in CPTP CDNA indicate numbers of base pair in the clone generated by cleavage and the scale of the map is shown in bp. (B) Nucleotide and deduced amino acid sequences of the CPTP1 CDNA. The nucleotide and the amino acid residues are numbered from the codon (CGC) and the arginine residue (R) is derived downstream from the linker sequence (GAATTCGCGGCCGC). Amino acid residues are denoted by the standard single letters underneath the nucleotide sequence. Termination codon is marked with asterisks. PESP (potential phosphorylation site by MAP kinase), S/TXXD/E(potential phosphorylation sequences by CKII), FKVRES (sequence found in SH2), GXGXXG (nucleotide-binding site) and another conserved motif of PTP (FWXMVW) are underlined. Catalytic domain of PTP (VHCSAGIGRSG) and TWPD are shown by open box. 


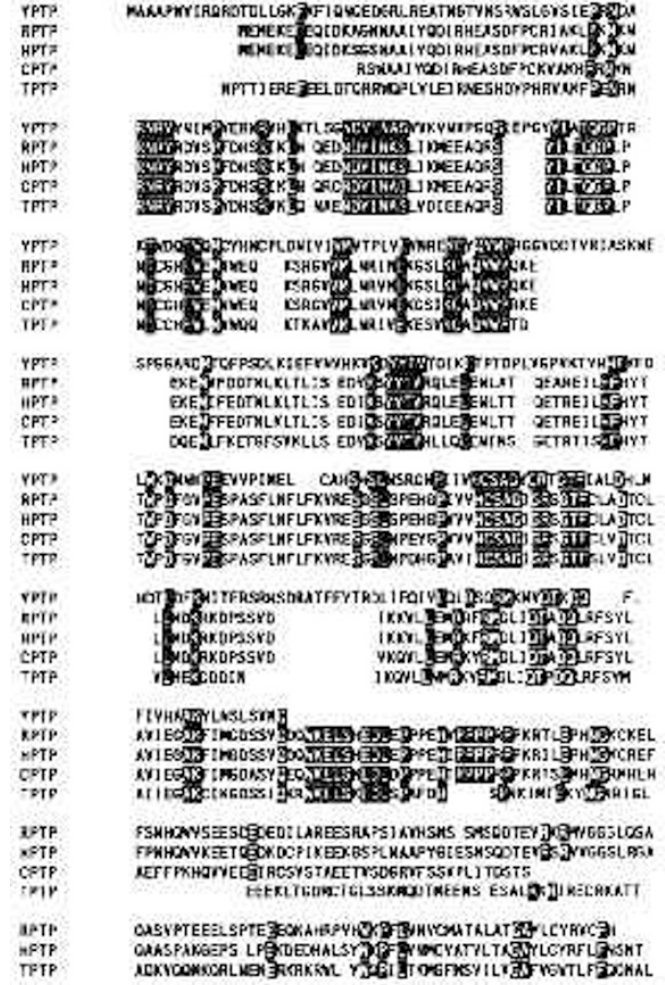

Figure 4. Amino acid sequence alignment of chicken PTP1 (CPTP), yeast PTP (YPTP), rat brain PTP (RPTP), human placenta PTP1B (HPTP), and human T-cell PTP (TPTP). The completely conserved amino acids are shown in black. Gaps (blank space) are introduced to maximize amino acid alignment. The underlined amino acid sequence of CPTP (position 309-356) is different from the PTPs found in higher eukaryotes length 435 amino acids of HPTP1B. HPTP1B, TPTP and RPTP contain a C-terminal hydrophobic domain, which could function in targeting or localization of the protein to the cellular membrane. By contrast the Cterminus of CPTP1 was different from those of these nontransmembrane-type PTPs of higher eukaryotes. Therefore, CPTP1 does not have a C-terminal targeting sequences as other mammalian PTPs. From this result it was suggested that the CPTP1 belongs to another nontransmembrane-type PTP localized in cytoplasmic compartment.

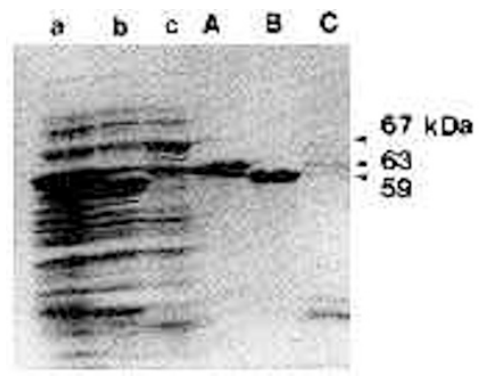

Figure 5. Affinity-purification of CPTP1-1, CPTP1, and HPTP1B GST-fusion proteins expressed in $E$. coli. Bacterial lysates shown in lanes $a, b$, and $c$ were affinity-purified on $\mathrm{S}$-hexylglutathione agarose bead and the purified proteins are shown in lanes $\mathrm{A}, \mathrm{B}$, and $C$ lanes. Lanes a and A, HPTP1B; lanes b and B, CPTP1-1; lanes $c$ and $C$, CPTP1. Molecular weights of isolated CPTP1-1, CPTP1 and HPTP1B fusion proteins are identified with 59,67 , and $63 \mathrm{kDa}$ marker proteins.

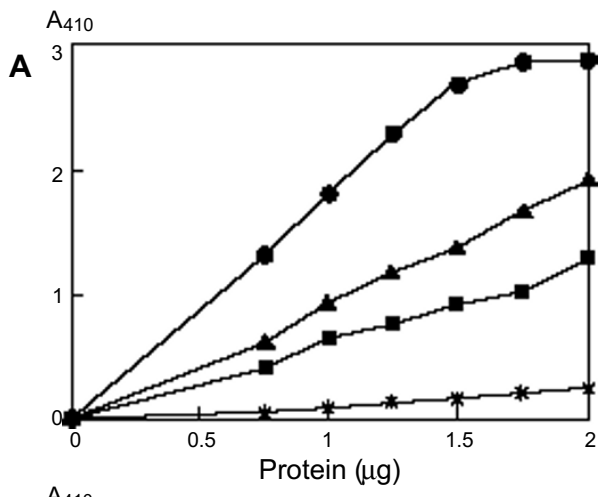

$\mathrm{A}_{410}$

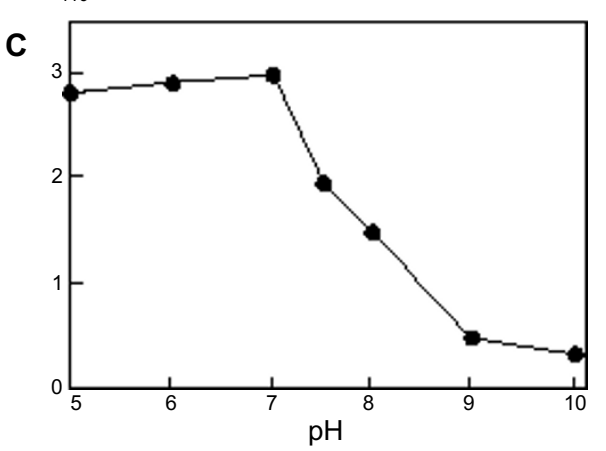

$\mathrm{A}_{410}$
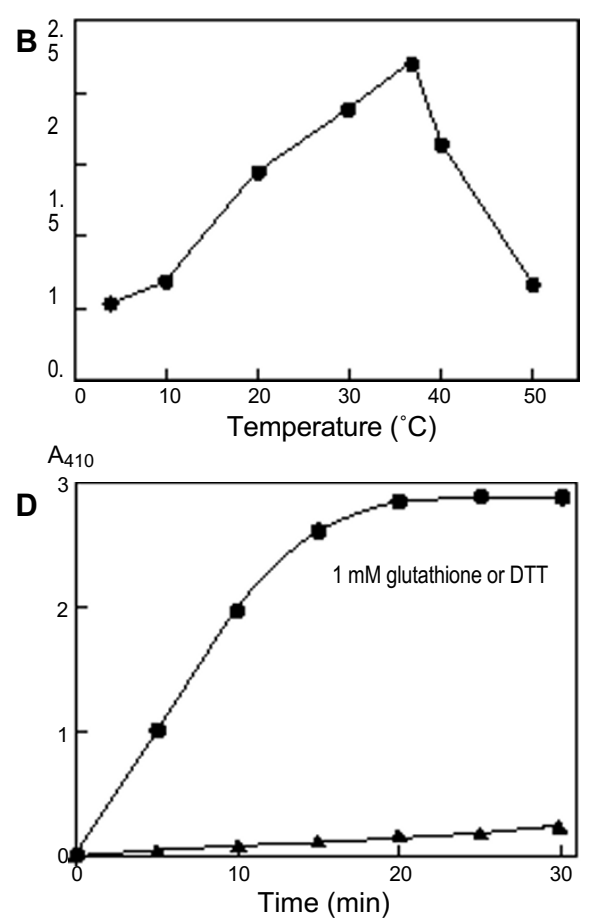

Figure 6. Determination of phosphatase activity. (A) Comparison of phosphatase activities of CPTP1-1, CPTP1, and

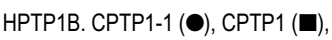
and HPTP1B $(\mathbf{\Delta})$ were assayed at the indicated concentrations for their ability to hydrolyze pNPP as described in Materials and Methods. As a control, GST protein was assayed under the same conditions (*). (B) Effect of temperature on phosphatase activity of CPTP1-1. (C) Effect of $\mathrm{pH}$ on phosphatase activity of CPTP1-1. (D) pNPP hydrolytic activities of CPTP1-1 in the presence (O) and absence $(\boldsymbol{\Delta})$ of $1 \mathrm{mM}$ glutathione or dithiothreitol. 


\section{Enzyme activity of CPTP1}

To characterize the activity of CPTP1, the GST-CPTP1 fusion cDNA construct was expressed in E. coli and purified by the method using glutathione-agarose affinity chromatography (Figure 5). On an analysis by SDS/PAGE, the isolated CPTP1-1, a C-terminal truncated form of CPTP1, and HPTP1B showed single bands, but the full-length CPTP1 showed several faint bands with different mobilities, suggesting that the product was degraded. In addition its recovery was low. Since thrombin treatment did not result in the cleavage of GST-CPTP1 and GST-HPTP1B fusion proteins, carrier-free PTP proteins could not be obtained.

To assay phosphatase activity of the purified recombinant PTPs, the fusion proteins were added to the reaction mixture containing phosphatase substrate, pNPP. As shown in Figure 6A, hydrolysis of pNPP was dependent on concentration of these PTPs and phosphatase activity of CPTP1-1 was shown to be higher (2.6 fold at $1 \mu \mathrm{g}$ of PTP) than those of full-length CPTP1 and HPTP1B, suggesting that C-terminal part of this enzyme had negative regulatory function or it might be cleaved for full enzyme activity in the cell. The optimum temperature of CPTP1-1 phosphatase activity was $37^{\circ} \mathrm{C}$ (Figure 6B) and hydrolysis of pNPP occurred easily under acidic conditions, although the reaction displayed a broad $\mathrm{pH}$ optimum between 5 and 7 (Figure $6 \mathrm{C})$. This optimal $\mathrm{pH}$ profile also distinguished CPTP1-1 from HPTP1B, which hydrolyzed pNPP optimally at $\mathrm{pH}$ 5.0-5.5 (Tonks et al., 1988b). As observed in other phosphatases, PTP-dependent hydrolysis of pNPP absolutely required reducing agent such as dithiothreitol or glutathione (Figure 6D).

\section{Inhibition of phosphatase activity}

Sodium vanadate, a potent inhibitor of the known PTPs, strongly inhibited the pNPPase activity of the CPTP1-1: half and complete inhibition occurred at $300 \mathrm{mM}$ and 10 $\mathrm{mM}$, respectively (Figure 7A). All of the known PTPs contain a critical cysteine residue in catalytic site that is proposed to act as the nucleophile, forming a thioester intermediate and initiates hydrolysis of the phosphate ester linkage with the phenyl side chain (Streuli et al., 1989, 1990; Guan and Dixon, 1990; Guan et al., 1991). When the enzyme is treated with alkylating agents, the phosphatase activity was completely blocked by modification of this cysteine residues. The CPTP1-1 was also sensitive to formaldehyde, undergoing the same inhibition mechanism (Figure 7B). The inhibitory action of formaldehyde to CPTP1-1 was stronger than that of sodium vanadate: half maximal inhibition by formaldehyde occurred at $3 \mu \mathrm{M}$ and total inhibition occurred at $100 \mu \mathrm{M}$. The result confirmed that the cysteine residue is critical to this tyrosine phosphatase activity.
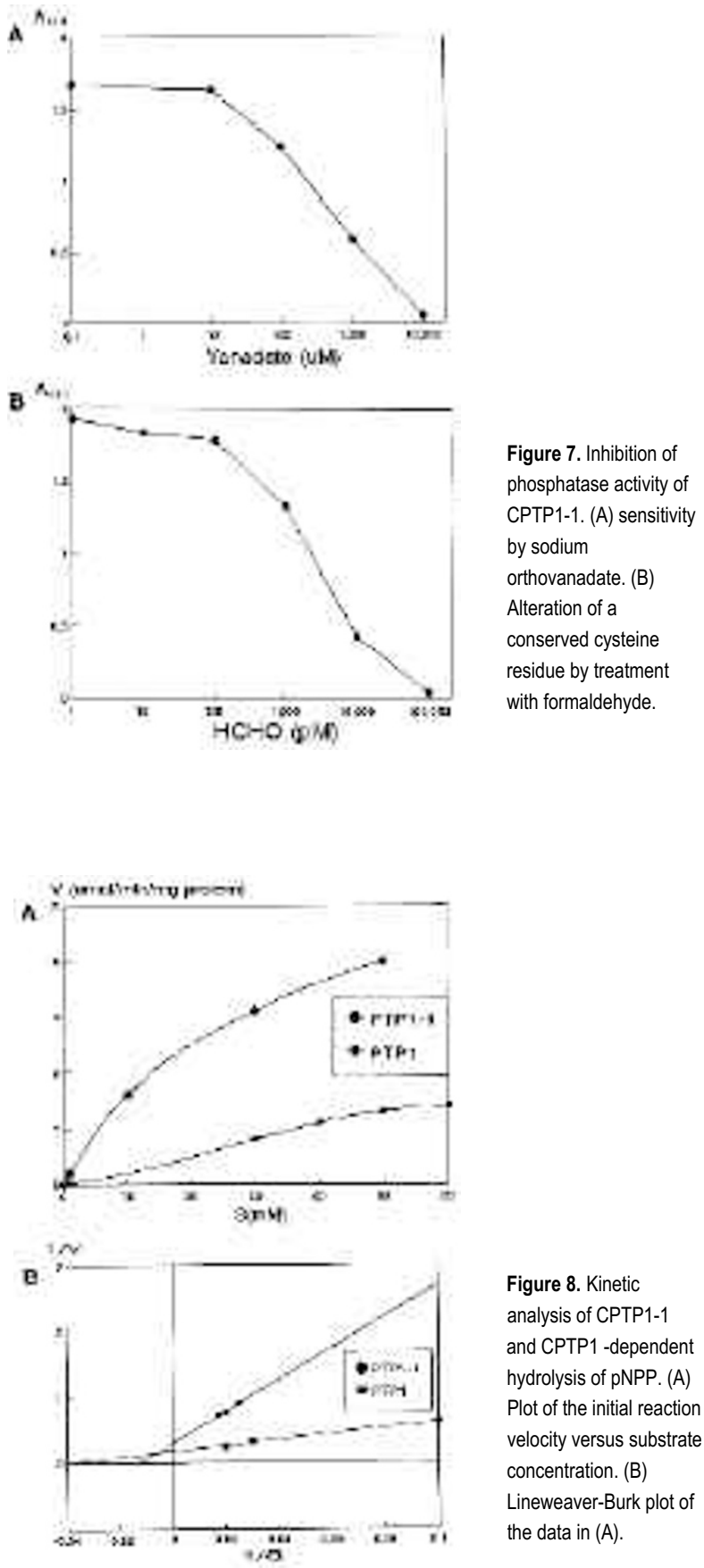

Figure 8. Kinetic analysis of CPTP1-1 and CPTP1 -dependent hydrolysis of pNPP. (A) Plot of the initial reaction velocity versus substrate concentration. (B) Lineweaver-Burk plot of the data in $(A)$

\section{Kinetic analysis of pNPP cleavage by CPTP1 and CPTP1-1}

Hydrolysis of pNPP was measured in the presence of CPTP1 and CPTP1-1 with various concentrations of substrate (Figure 8A). A Lineweaver-Burk plot of the data revealed that the $K_{\mathrm{m}}$ for the CPTP1 was $83.3 \mathrm{mM}$ using pNPP as substrate and $\mathrm{V}_{\max }$ was $3.6 \mu \mathrm{mol}$ per 
min per mg of the enzyme (Figure 8B). By contrast, $K_{m}$ value of CPTP1-1 was $25 \mathrm{mM}$ pNPP and $\mathrm{V}_{\max }$ was 6 $\mu \mathrm{mol}$ per min per $\mathrm{mg}$ of the protein. Thus, deletion of 72 amino acids in C-terminal side resulted in higher substrate affinity and phosphatase activity than full CPTP1 protein. This result indicated that the $\mathrm{C}$-terminal region of the CPTP1 protein acts as negative regulator domain for phosphatase activity.

\section{Acknowledgement}

This study was supported by the by the Genetic Engineering program(1993), Ministry of Education, Republic of Korea.

\section{References}

Brown-Shimer, S., Johnson, K. A., Lawrence, J. B., Johnson, C., Bruskin, A., Green, N. R. and Hill, D. E. (1990) Molecular cloning and chromosome mapping of the human gene encoding protein phosphotyrosyl phosphatase 1B. Proc. Natl. Acad. Sci. U.S.A. 87: $5148-5152$

Cantley, L. C., Auger, K. R., Carpenter, C., Duckworth, B., Graziani, A., Kapeller, R. and Soltoff, S. (1991) Oncogenes and signal transduction. Cell 64: 281-302

Carlino, A., Toledo, H., Skaleris, D., Delisio, R., Weissbach, H. and Brot, N. (1992) Interactions of liver Grp78 and Escherichia coli recombinant Grp78 with ATP. Proc. Natl. Acad. Sci. U.S.A. 89: 2081-2085

Charbonneau, H., Tonks, N. K., Kumar, S., Diltz, C. D., Harrylock, M., Cool, D. E., Krebs, E. G., Fisher, E. H. and Walsh, K. A. (1989) Human placenta protein-tyrosinephosphatase: amino acid sequence and relationship to a family of receptor-like proteins. Proc. Natl. Acad. Sci. U.S.A. 86: 5252-5256

Chernoff, J., Schievella, A. R., Jost, C. A., Erikson, R. L. and Neel, B. G. (1990) Cloning of a cDNA for a major human protein-tyrosine-phosphatase. Proc. Natl. Acad. Sci. U.S.A. $87: 2735-2739$

Cool, D. E., Tonks, N. K., Charbonneau, H., Walsh, K. A., Fisher, E. H. and Krebs, E. $G$. (1989) cDNA isolated from a human T-cell library encodes a member of the proteintyrosine-phosphatase family. Proc. Natl. Acad. Sci. U.S.A. 86: 5257-5261

Cool, D. E., Tonks, N. K., Charbonneau, H., Fisher, E. H. and Krebs, E. G. (1990) Expression of a human $\mathrm{T}$-cell protein-tyrosine phosphatase in baby hamster kidney cells. Proc. Natl. Acad. Sci. U.S.A. 86: 7280-7284

Dunphy, W. G. and Kumagai, A. (1991)The cdc25 protein contains an intrinsic phosphatase activity. Cell 67: 189-196

Fischer, E. H. Charbonneau, H., and Tonks, N. K. (1991) Protein tyrosine phosphatases: a diverse family of intracellular and transmembrane enzymes. Science 253: 401-406

Frangioni, J. V., Beahm, P. H., Shifrin, V., Jost, C. A. and Neel, B. G. (1992) The transmembrane tyrosine phosphatase PTP-1B localizes to the endoplasmic reticulum via its 35 amino acid C-terminal sequence. Cell 68: 545-560
Grunstein, M. and Hogness, D. S. (1975) Coloney hybridization: a method for the isolation of cloned DNAs that contain a specific gene. Proc. Natl. Acad. Sci. U.S.A. 72: 3961-3965

Guan, K., Haun, R. S., Waston, S. J., Geahlen, R. L. and Dixon, J. E. (1990) Cloning and expression of a protein-tyrosine-phosphatase. Proc. Natl. Acad. Sci. U.S.A. 87: 1501-1505

Guan, K. and Dixon, J. E. (1990) Protein tyrosine phosphatase activity of an essential virulence determinant in Yersinia. Science 249: 553-556

Guan, K., Broyles, S. S. and Dixon, J. E. (1991) A Tyr/Ser protein phosphatase encoded by vaccinia virus. Nature 350: 359-362

Guan, K., Deschenes, R. J. Qiu, H. and Dixon, J. E. (1991) Cloning and expression of a yeast protein tyrosine phosphatase. J. Biol. Chem. 266: 12964-12970

Pot, D. A., Woodford, T. A., Remboutsika, E., Haun, R. S. and Dixon, J. E. (1991) Cloning, bacterial expression, purification, and characterization of the cytoplasmic domain of rat LAR, a receptor-like protein tyrosine phosphatase. J. Biol. Chem. 266: 19688-19696

Sambrook, J., Fritsch, E. F., and Maniatis, T. (1990) Molecular Cloning: A Laboratory Manual, Cold Spring Harbor Laboratory, Cold Spring Harbor

Sanger, F., Nicklen, S. and Coulson, A. R. (1977) DNA sequencing with chainterminating inhibitors. Proc. Natl. Acad. Sci. U.S.A. 74: 5463-5467

Smith, D. B. and Johnson, K. S. (1988) Single-step purification of polypeptides expressed in Escherichia coli as fusions with glutathione S-transferase. Gene 67: 31 40

Streuli, M., Krueger, N. X., Tsai, A. Y. M. and Saito, H. (1989) A family of receptorlinked protein tyrosine phosphatases in humans and Drosophila. Proc. Natl. Acad. Sci. U.S.A. 86: $8698-8702$

Streuli, M., Krueger, N. X., Thai, T., Tang, M. and Saito, H. (1989) Distinct functional roles of the two intracellular phosphatase like domains of receptor-linked protein tyrosine phosphatases LCA and LAR. EMBO J. 9: 2399-2407

Tonks, N. K., Dilts, C. D. and Fisher, E. H. (1988a) Purification of the major proteintyrosine-phosphatases of human placenta. J. Biol. Chem. 263: 6722-6730

Tonks, N. K., Dilts, C. D. and Fisher, E. H. (1988b) Characterization of the majo protein-tyrosine-phosphatases of human placenta. J. Biol. Chem. 263: 6731-6737

Zander, N. F., Lorenzen, J. A., Cool, D. E., Tonks, N. K., Daum, G., Krebs, E. G. and Fisher E. H. (1991) Purification and characterization of a human recombinant T-cel protein-tyrosine-phosphatase from a baculovirus expression system. Biochemistry 30 : 6964-6970 